\title{
COMPARISON OF FATIGUE PARAMETERS OF ALKALI- ACTIVATED AND ORDINARY PORTLAND CEMENT BASED CONCRETES
}

\author{
Seitl Stanislav ${ }^{1}$, Bílek Vlastimil ${ }^{2}$, Keršner Zbyněk ${ }^{3}$ \\ ${ }^{1}$ High cycle fatigue group, Institute of Physics of Materials, Academy of Sciences of the Czech Republic, Czech \\ Republic \\ ${ }^{2}$ Testing laboratory, ŽPSV, OHL GROUP, Uherský Ostroh, Czech Republic \\ ${ }^{3}$ Brno University of Technology, Institute of Structural Mechanics, Faculty of Civil Engineering, Czech Republic
}

\begin{abstract}
Concretes used in civil structures are usually made on ordinary Portland cement (OPC) base. Alkali activated concretes (AAC) are considered as a perspective building materials. They show high strength, good durability, and good resistance to aggressive agents etc. This paper introduces the values of the basic fatigue parameters of both types of concrete; the alkali-activated concrete is prepared as a new material for the potential production of concrete elements developed by ZPSV, a.s. company. The concrete mixtures have a similar utilization and therefore the fatigue parameters can be compared. The specimens were prepared and tested under static (compressive strength) and cyclic loading (fatigue parameters Wöhler curve). The experimentally obtained results (mechanical and fatigue) of both types of concrete are compared and the suitability of these types of composites for their application is discussed.
\end{abstract}

Keywords: Fatigue, Wöhler curve, Fracture mechanics, Alkali-Activated Concrete, concrete C45/55

\section{INTRODUCTION}

Alkali activated concretes (AAC) are considered to be an alternative to Portland cement concrete. They represent promising building material. Their properties were demonstrated not only in many academic papers; see e.g. [1, 2] but also in service in many different applications in Belgium, Finland, former USSR, China, and Australia ... [2]. They show high strength, good durability, and good resistance to aggressive agents etc. But their fatigue behaviour has hardly been studied even though railway sleepers were experimentally produced from AAC in Russia and Spain $[3,4]$.

Some AACs for practical use were developed at ZPSV, a.s. company formerly and some experimental elements were produced from these concretes [5,6]. As a higher strength of $\mathrm{AAC}$ is reached due to reduction of the water to binder ratio, also fatigue parameters start to get more and more important.

In the case of OPC concretes, the sustainable development of concrete structures is oriented to subtle constructions where the fatigue behaviour plays a crucial role. Similar trends can be expected in the case of AAC.

The knowledge about fracture parameters of various kinds of concrete is one of indispensable fact nowadays, see e.g. [7] for fracture parameters of self compacted concrete, [8] for fracture parameters of fibre concrete with waste aggregates [9] for fracture parameters of natural fibre reinforced concrete etc.

The limited knowledge about the long-term behavior or the effects of repeated loading on the properties of these materials caused a growing interest in the fatigue performance of concrete [10-15]. Furthermore, reliable data are needed for calibration of accurate models capable to predict the fatigue behavior of Alkali-Activated composites.

During the past three decades, a number of works pertaining to experimental and analytical methods of evaluating strength characteristics of concrete have been published on varied specimen types, curing times, testing methods, etc. Fatigue failure occurs when a concrete structure fails at less than a design load after being exposed to a large number of stress cycles. Fatigue may be defined as a process of progressive and permanent internal damage in a material subjected to repeated loading. Fatigue loading is usually divided into three categories: low-cycle and high-cycle loading and super-high-cycle fatigue [10].

In general, parameters such as loading conditions, load frequency, boundary conditions, stress level (stress ratio), number of cycles, matrix composition, environmental conditions and mechanical properties will influence the fatigue performance of concrete [10-13]).

In this paper, fatigue tests of Alkali-Activated and C45/55 concretes for building elements/constructions/structures under constant-amplitude cyclic loads were carried out to 
obtain information about the fatigue behaviour in different concrete compositions. The experimental measurements were performed at two levels. The first one was a static measurement of AAC (represented by values of compressive strength). The second level is related to the high-cycle fatigue - Wöhler curves [16] of both studied concretes were determined and compared. The obtained experimental results are discussed in terms of suitability for use in construction under fatigue load.

\section{EXPERIMENT}

\subsection{Materials}

The ground-granulated blast furnace slag (GBFS) used was produced in the Czech Republic and it is ground at the Kotouc Stramberk company to specific surface $380 \mathrm{~m}^{2} / \mathrm{kg}$. For the chemical composition of GBFS see Table 1.

Ordinary Portland Cement CEM I coming from the Mokra cement plant has specific surface $384 \mathrm{~m}^{2} / \mathrm{kg}$. Commercially produced sodium water glass with silicate modulus 2.0 was used for AAC preparation as well as $50 \%$ solution of potassium hydroxide. Superplasticizers on polysulphonated napthalenes basis and on polycarboxylates basis (Chryso company) were used to enhance the workability. Concretes were prepared using drinking water, natural sand $0 / 4 \mathrm{~mm}$ and two narrow fractions of crushed aggregates $4 / 8$ and $8 / 16$ $\mathrm{mm}$ respectively.

Table 1: Chemical composition [\%] of ground granulated blast furnace slag (GBFS)

\begin{tabular}{|l|l|l|l|l|l|l|}
\hline & $\mathrm{CaO}$ & $\mathrm{SiO}_{2}$ & $\mathrm{Al}_{2} \mathrm{O}_{3}$ & $\begin{array}{l}\mathrm{Fe}_{2} \mathrm{O} \\
3\end{array}$ & $\mathrm{MgO}$ & $\mathrm{SO}_{3}$ \\
\hline GBFS & 41.5 & 37.7 & 6.5 & 0.4 & 10.1 & 0.8 \\
\hline
\end{tabular}

All mixtures were mixed in a laboratory mixer in 30 litre volume, see Tab. 2 for composition of $1 \mathrm{~m}^{3}$ of concrete. Immediately after the mixing, tests of workability (cone flow with reversed Abrams cone) were performed (see Tab. 2 ) and the concrete was placed into steel moulds. For compressive tests $150 \mathrm{~mm}$ cubes were prepared, for other tests beams of $80 \times 80 \times 480 \mathrm{~mm}^{3}$ were made. The specimens were unmoulded at the age of 24 hours, enveloped by PEfoil in order to avoid the exchange of water with the environment and they were stored until the tests started at the age of 28 days.

Table 2: Composition and properties of fresh AA concrete

\begin{tabular}{|ll|c|}
\hline \multicolumn{1}{|c|}{} & & AAC \\
\hline GGBFS & $\mathrm{kg}$ & 450 \\
\hline Na-water glass & $\mathrm{kg}$ & 57 \\
\hline KOH - 50\% solution & $\mathrm{kg}$ & 42 \\
\hline water & $\mathrm{kg}$ & 125 \\
\hline plasticizer (PNS) & $\mathrm{kg}$ & 10 \\
\hline sand 0/4 mm & $\mathrm{kg}$ & 880 \\
\hline crushed aggregates 4/8 mm & $\mathrm{kg}$ & 400 \\
\hline crushed aggregates 8/16 mm & $\mathrm{kg}$ & 415 \\
\hline water to binder ratio & & 0.4 \\
\hline workability cone flow & $\mathrm{mm}$ & 580 \\
\hline
\end{tabular}

The material for manufacturing of the ordinary concrete test specimens was concrete $\mathrm{C} 45 / 55$ collected from a trial mix of a total volume of $1.8 \mathrm{~m}^{3}$ at the concrete plant in BrnoBosonohy on 26. 5. 2011. The concrete was designed for the environmental exposure XC2 (wet, sometimes dry environment), using aggregates with grains of a maximum size $22 \mathrm{~mm}$ and cement CEM I $42.5 \mathrm{R}$.

The consistency of the fresh concrete was determined by the method of slump, and after 10 minutes it reached the value of $165 \mathrm{~mm}$ for concrete class C45/55 - S3.

In order to ensure a good homogeneity of the tested concrete, the experiment sets were prepared at a concrete mixing plant. Note that the results of homogeneity according to the Czech Standard (ČSN 73 2011) are very good.

\subsection{Static and Fatigue Methods for obtaining Selected Fracture Mechanical Parameters}

As a basic static parameter, the compressive cube strength was chosen. Cubes with edge lengths of $150 \mathrm{~mm}$ were used for the determination of the compressive strength values. Because of the gradually increasing age of the concrete specimens during the dynamic tests, the above-mentioned specimens were tested at various ages.

The fatigue properties were obtained from three point bending tests of beam specimens with a central edge notch with the relative depth of $a / W=0.10$. The nominal dimensions of the beams were $100 \times 100 \times 400 \mathrm{~mm}^{3}$, span length $300 \mathrm{~mm}$ for $\mathrm{C} 45 / 55$ and $80 \times 80 \times 240 \mathrm{~mm}^{3}$ span length $200 \mathrm{~mm}$ for AAC. The initial notch was created by a diamond blade saw.

The experimental test program was carried out at the Laboratory of High Cycle Fatigue Group at the Institute of Physics of Materials. The values of the temperature and relative humidity were controlled being maintained at $22 \pm 2{ }^{\circ} \mathrm{C}$ and $50 \%$. The fatigue tests for determination of the Wöhler curves were carried out in a computer-controlled servohydraulic testing machine (Shimadzu) see Fig. 1.

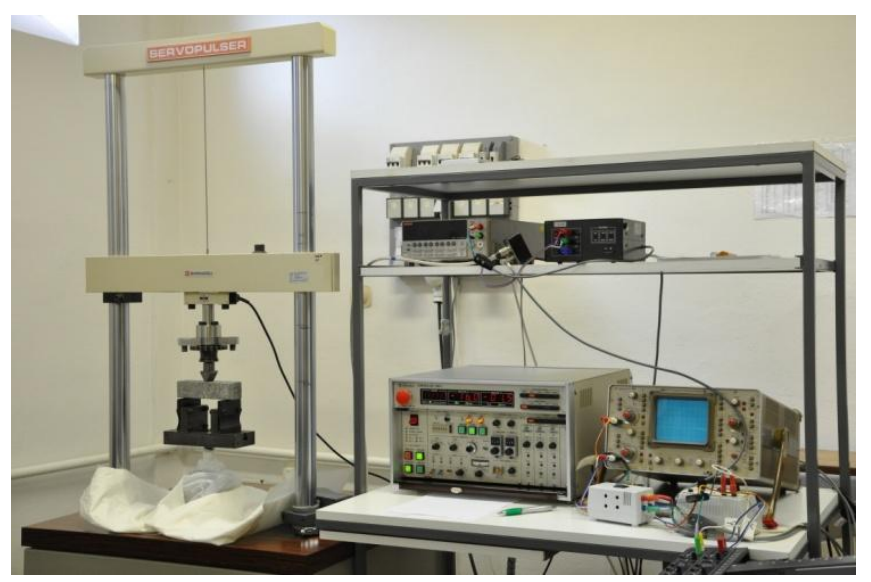

Fig. 1: Setup for measurement of fatigue parameters 
Fatigue testing was conducted under load control. The stress ratio was $R=P_{\min } / P_{\max }=0.1$, where $P_{\min }$ and $P_{\max }$ refer to the minimum and maximum load of a sinusoidal wave in each cycle. The load frequency used for all repeated-load tests was approximately $10 \mathrm{~Hz}$. The fatigue failure numbers of specimens were recorded [17].

Concrete specimens were loaded in the range of high-cycle fatigue; the upper limit to the number of cycles to be applied has been selected as 2 million cycles. The test finished when the failure of the specimen occurred or the upper limit of the number of cycles was reached, whichever occurred first.

\section{RESULTS AND DISCUSSION}

\subsection{Static Results}

The selected static and fatigue parameters resulting for both types of concrete are presented in this part.

The values of the compressive cubic strength for AAC were measured after 24 hours and 2, 3, 7, 28 and 90 days as shown in Table 3 in order to capture the progress/change of the parameters in time.

Table 3: Compressive strength results for Alkali-Activated concrete.

\begin{tabular}{|c|c|c|c|}
\hline $\begin{array}{l}\text { Age } \\
\text { [days] }\end{array}$ & $\begin{array}{l}\text { Specimen } \\
\text { number }\end{array}$ & $\begin{array}{l}\text { Strength of } \\
\text { material } \\
{[\mathrm{MPa}]}\end{array}$ & $\begin{array}{l}\text { Average value of } \\
\text { strength of material } \\
{[\mathrm{MPa}]}\end{array}$ \\
\hline \multirow{3}{*}{1} & K1 & 21.0 & \multirow{3}{*}{20.7} \\
\hline & $\mathrm{K} 2$ & 20.1 & \\
\hline & K3 & 21.1 & \\
\hline \multirow{3}{*}{2} & K4 & 39.6 & \multirow{3}{*}{40.3} \\
\hline & K5 & 40.2 & \\
\hline & K6 & 41.1 & \\
\hline \multirow{3}{*}{3} & K7 & 46.0 & \multirow{3}{*}{49.0} \\
\hline & K8 & 50.7 & \\
\hline & K9 & 50.4 & \\
\hline \multirow{3}{*}{7} & K10 & 59.5 & \multirow{3}{*}{63.1} \\
\hline & K11 & 63.7 & \\
\hline & K12 & 66.0 & \\
\hline \multirow{3}{*}{28} & K13 & 79.7 & \multirow{3}{*}{78.5} \\
\hline & K14 & 76.6 & \\
\hline & K15 & 79.2 & \\
\hline \multirow{3}{*}{90} & K16 & 91.1 & \multirow{3}{*}{84.3} \\
\hline & K17 & 88.5 & \\
\hline & K18 & 73.4 & \\
\hline
\end{tabular}

The analytical expressions for the regression curves were determined as approximations of the compressive strength values over time, see Chart 1 . The regression was done for different numbers of days to fit the best prediction of the evolution of concrete parameters. For example, the fit number 1 covering all ages measured is not so appropriated for regression due to its steady increase.

The values of coefficients for different age are mentioned in Table 4 together with coefficient of determination $R^{2}$. The last row corresponds to $\mathrm{C} 45 / 55$ concrete class that was taken from $[14,15]$.

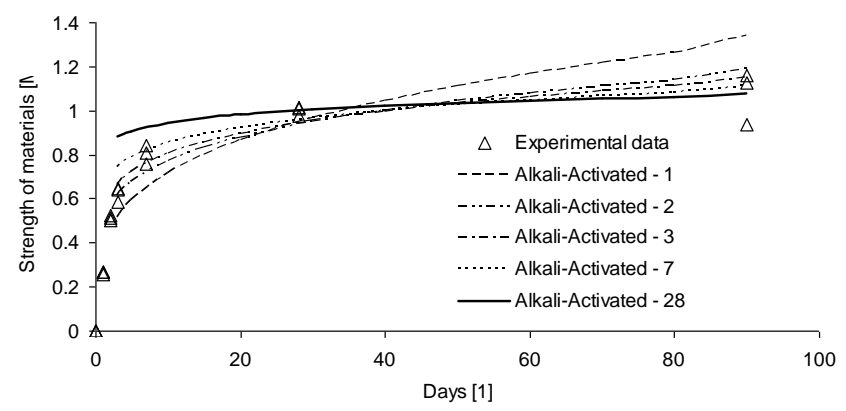

Chart 1: Approximation curves for relative maximum loading force for Alkali-Activated concrete.

Table 4: Exponents of the analytical equations for approximation curves $y=a \times x^{b}$, for concrete $C 45 / 55$ taken from $[14,15]$.

\begin{tabular}{|l|l|l|l|}
\hline & \multicolumn{4}{|l|}{ Coefficients of regression curves } \\
\hline & $a$ & $b$ & $R^{2}$ \\
\hline $\begin{array}{l}\text { Alkali- } \\
\text { Activated 1 }\end{array}$ & 0.3821 & 0.2721 & 0.7905 \\
\hline $\begin{array}{l}\text { Alkali- } \\
\text { Activated 2 }\end{array}$ & 0.5009 & 0.1871 & 0.8802 \\
\hline $\begin{array}{l}\text { Alkali- } \\
\text { Activated 3 }\end{array}$ & 0.5603 & 0.1556 & 0.8582 \\
\hline $\begin{array}{l}\text { Alkali- } \\
\text { Activated 7 }\end{array}$ & 0.6558 & 0.1138 & 0.7510 \\
\hline $\begin{array}{l}\text { Alkali- } \\
\text { Activated 28 }\end{array}$ & 0.8250 & 0.0576 & 0.1931 \\
\hline C45/55 & 0.7173 & 0.0983 & 0.8548 \\
\hline
\end{tabular}

\subsection{Fatigue Results}

The fatigue results are shown in the graphs of Charts 2, 3 and 4 , where the maximum bending stress ( $\square \square \square \square \mathrm{MPa}$ ) applied during the fatigue experiments is plotted against the logarithm of the number of cycles to failure or at $2 \times 10^{6}$ cycles $[\mathrm{N}]$, limit number of cycles, for run-outs i.e. for unbroken specimens. Along with data points, the analytical expressions for the curves were obtained assuming the following form:

$$
\sigma=a \times N^{b}
$$


The fatigue behavior of a heterogeneous material like concrete is far from being ideal and the results are usually highly scattered; therefore, it is necessary to determine not only the analytical expression but also the index of dispersion.

Firstly, the fatigue results obtained from the tests conducted under varying maximum bending stress level are summarized in Chart 2 for both concretes studied. The Wöhler curve of AAC is rather flat providing values considerably lower then for the silicate-based composites $(\mathrm{C} 45 / 55)$. The AAC curve exhibits many run-outs for $2 \times 10^{6}$ cycles even at high stress levels.

\subsection{Discussion Fatigue Results}

As the authors show in $[14,15]$, the fatigue tests lasted a long time, which is problematic from the point of view of the ageing of the material of the specimen. Because of this, the data obtained from the fatigue tests were normalized to 28 days static strength (see Tab. 4) when defining the approximation curves for the compressive strength measurement over time.

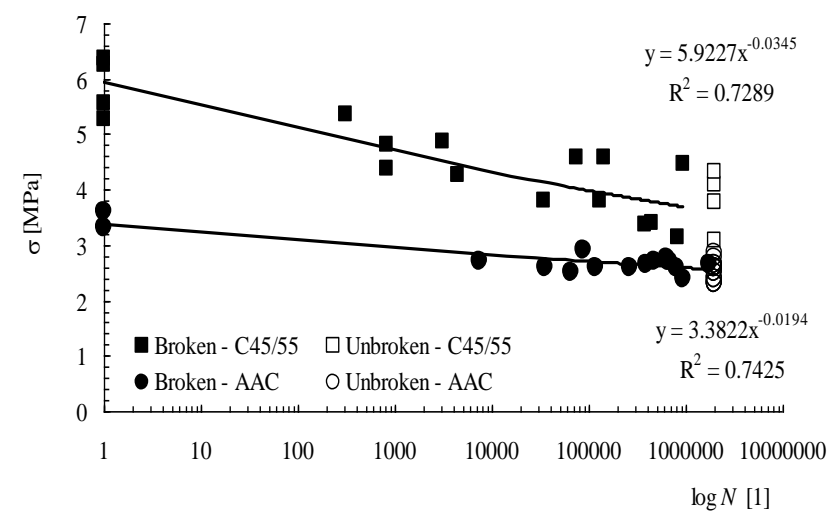

Chart 2: S-N diagrams for the tested concrete (black symbol: broken specimen; white symbol: unbroken specimen).

The experimental data and fitted fatigue data (using the power regression curve of compressive strength from Tab. 2) are shown in Chart 3 for the C45/55 concrete class. If the data are recalculated to the 28 days static strength the oldest measured specimens showing higher values of the stress would provide a more favorable index of dispersion. According to equation (1), the power function and correlation coefficient for $\mathrm{C} 45 / 55$ class concrete are the following:

$$
\sigma=5.9227 \times N^{-0.0345} \text { and } R^{2}=0.7289
$$

and for the normalized approximation curves:

$\sigma=5.3725 \times N^{0.0337}$ and $R^{2}=0.8435$.

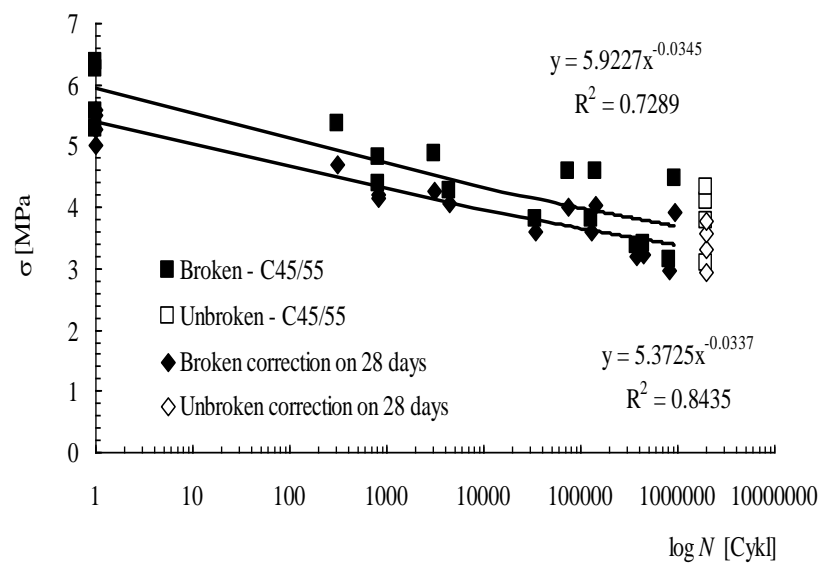

Chart 3: Lifetime data for concrete class C45/55 normalized to the 28 days static strength.

The measured data and corrected fatigue data (using the power regression curve of compressive strength from Tab. 2) are shown in Chart 4 for the AAC. If the data are normalized to the 28 days static strength, the oldest measured specimens show higher values of the expected stress. The index of dispersion has practically the same quality. According to equation (1), the power function and coefficient of determination for AAC are follows:

$\sigma=3.3822 \times N^{0.0194}$ and $R^{2}=0.7425$

and for corrected by approximation curves:

$\sigma=2.9555 \times N^{0.0193}$ and $R^{2}=0.7571$.

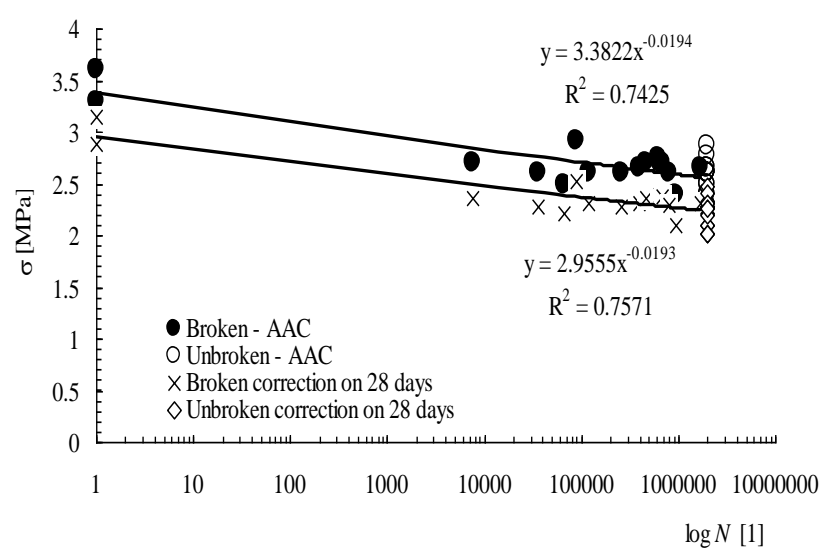

Chart 4: Time corrected data for Alkali-Activated concrete for 28 days.

The AAC material shows lower values of tensile strength than the C45/55 but, on another hand, higher fatigue resistance, as shown in Chart 5. This is sustained by the value of the exponent in the approximation curve $(-0.0193$ in the case of the AAC concrete and to compare -0.0337 in case of the $\mathrm{C} 45 / 55$ concrete) and supported by a large amount of run-outs up to 2 million cycles. 


\section{CONCLUSIONS}

From the presented experimental research work following conclusions can be drawn:

Two concrete types were investigated, namely,-the AAC and the $\mathrm{C} 45 / 55$ concretes, both being different based composites from a chemical point of view, used for building constructions.

The Alkali-Activated concrete exhibits values of the tensile fatigue parameters much lower in Chart 2 than those of C45/55 concrete whereby similar values of the coefficient of variation are obtained for both when the age method is used.

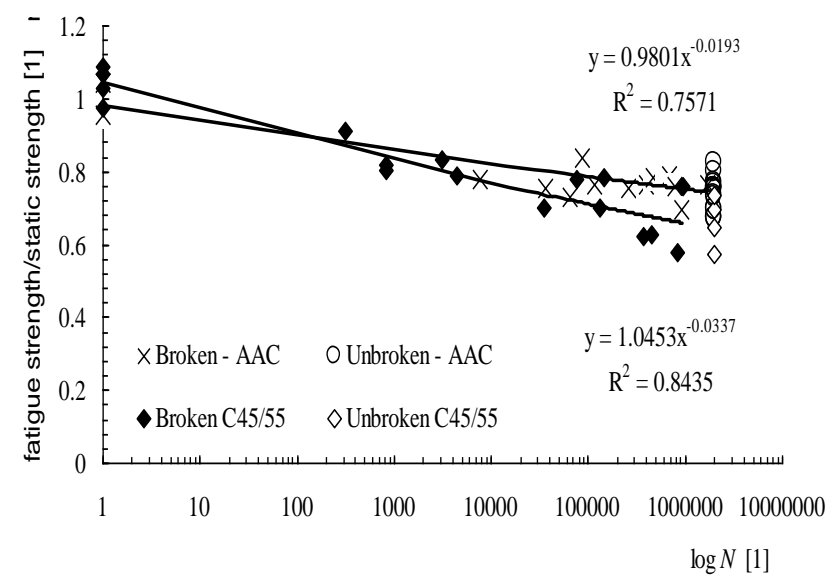

Chart 5: Comparison between AAC and C45/55 concrete fatigue behavior. The values are normalized by the static tensile strength.

Note that the scatter of experimental results of all composite materials is standard and is acceptable in terms of practical use.

It can be concluded that the AAC material presents lower values of tensile strength than the $\mathrm{C} 45 / 55$ but, on another hand, higher fatigue resistance, as shown in Chart 5. This is sustained by the value of the exponent in the approximation curve (-0.0193 in the case of the AAC concrete) and supported by a large amount of run-outs up to 2 million cycles.

Therefore, from a fatigue point of view the AAC proves to be suitable for building elements, structures and constructions, though care must be taken concerning the tensile stress. Note that fracture and fatigue parameters are used as input data when modeling elements, structures and constructions, see e.g. [18,19].

\section{ACKNOWLEDGEMENTS}

This paper was written with the support of the grant projects: No. M100411204, No. CZ. 107/2.3.00/20.0197 and No. TACR TA03010501

\section{REFERENCES}

[1] Shi, C., Krivenko, P.V., Roy, D., Alkali-Activated Cements and Concretes, Taylor Francis, 2006, ISBN I3: 978-0-415-70004-7

[2] Alkali Activated Materials, Rilem State-of.the-Art Reports TC 224-AAM, Provis, J.L., van Deventer, J.S.J. (Eds.), RILEM 2014, ISBN 978-94-007-76715

[3] Petrova, T., Dzhashi, N., Poletaev, A., Durability of slag-alkaline concretes, 2nd Int. Symp. NonTraditional Cement and Concrete, Bilek and Kersner (Eds), (2005), Brno, pp. 61-68, ISBN 80-214-2853-8

[4] Palomo, A., Industrial application of alkali activated Concrete, lecture for ZPSV a.s. company, unpublished

[5] Bilek, V., Opravil, T., Soukal, F., Searching for practically applicable alkali-activated concretes, $1^{\text {st }}$ Int. Conf. on Advances in Chemically-Activated Materials (CAM 2010), Shi and Shen (Eds), Jinan (China) (2010), pp. 28-35, ISBN: 978-2-35158-1018

[6] Bilek, V., Self-compacting alkali activated concrete for production of concrete elements, $36^{\text {th }}$ Conf on Our world in concrete structures, Tam, Ong, Teng, Zhang (Eds), CI Premier, Singapore, (2011), ISBN 978-981-08-9528-0

[7] Korte, S., Boel, V., De Corte, W., De Schutter, G., Static and fatigue fracture mechanics properties of self-compacting concrete using three-point bending tests and wedge-splitting tests, Construction and Buildings Materials, V. 57, (2014), pp. 1-8

[8] Katzer, J., Domski, J., Optimization of fibre reinforcement for waste aggregate cement composite, Construction and Building Materials, V. 38, (2013), pp 790-795

[9] Merta, I., Tschegg, E.K. Fracture energy of natural fibre reinforced concrete, Construction and Building Materials, V. 40 (2013), pp. 991-997

[10] Lee, M.K., Barr, B.I.G. An overview of the fatigue behaviour of plain and fibre reinforced concrete, Cement \& Concrete Composites, V. 26, (2004), pp. 299-305

[11] Seitl, S., Bílek, V., Keršner, Z., Veselý, J., Cement based composites for thin building elements: Fracture and fatigue parameters, Procedia Engineering, V. 2(1), (2010), pp. 911-916,

[12] Kim, J.K., Kim, Y.Y. Experimental study of the fatigue behaviour of high strength concrete, Cement Concrete Res, V. 26(10), (1996), pp. 1513-1523

[13] Seitl, S., Keršner, Z., Bílek, V., Knésl, Z., Fatigue parameters of cement-based composites with various types of fiber, Key Engineering Materials, Vs. $417-$ 418, (2010), pp. 129-132

[14] Šimonová, H., Kucharczyková, B., Havlíková, I., Seitl, S., Kersner, Z. Complex Evaluation of Fatigue Tests Results of Plain C30/37 and C45/55 Class Concrete Specimen, Key Engineering Materials, Vs. 592-593, (2014), pp. 801-804

[15] Šimonová H., Havlíková, I., Keršner, Z., Seitl, S., Statistical Evaluation of Fatigue Tests of Plain 
C30/37 and C45/55 Class Concrete Specimens, VIII International Conference on Fracture Mechanics of Concrete and Concrete Structure, FraMCos-8, 11-14 March 2013, Toledo Spain eds. Mier, Ruiz, Andrade, Yu, Zhang, (2013), pp. 862-867, ISBN: 978-84-941004-1-3

[16] Castillo, E., Fernández-Canteli, A., A unified statistical methodology for modeling fatigue damage, Springer, 2009.

[17] Youliang Chena, Jing Nia, Ping Zhenga, Rafig Azzamb, Youcheng Zhoua, Wei Shao, Experimental research on the behaviour of high frequency fatigue in concrete, Engineering Failure Analysis, V. 18, (2011), pp. 1848-1857

[18] Pryl, D., Mikolaskova, J., Pukl, R., Modeling fatigue damage of concrete, Key Engineering Materials, V. 577-578, (2014), p. 385-388

[19] Pryl, D., Červenka, J., Pukl, R., Material model for finite element modelling of fatigue crack growth in concrete. Procedia engineering, Vol. 2, (2010) p. 203-212.

\section{BIOGRAPHIES}

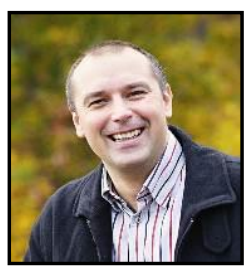

Ing. Stanislav Seitl, Ph.D. is a researcher of High Cycle Fatigue Group at Institute of Physics of Materials, Academy of Sciences of the Czech Republic. His scientific interest: Fatigue of materials and lifetime estimation, Two-parameter fracture mechanics, Numerical modeling and calculations of fracture-mechanics parameters.

www.ipm.cz

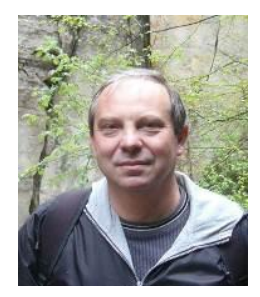

Ing. Vlastimil Bílek, Ph.D. is a research worker at ZPSV a.s. company. His topics of interest include durability of concrete, concrete with mineral admixtures, alkali activated concrete and application of these concretes in practice.

www.zpsv.cz

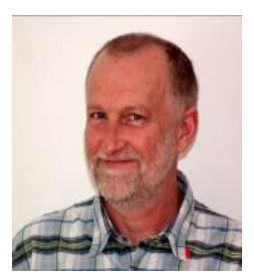

Prof. Ing. Zbyněk Keršner, CSc. is a researcher/lecturer at Brno University of Technology, Faculty of Civil Engineering, Institute of Structural Mechanics. His main research activities are focused to the field of application of fracture mechanics to quasi-brittle cement

based composites.

www.vutbr.cz 